\title{
Uso de leña y madera de bosques nativos en comunidades de la Cordillera del Vilcanota. Cusco
}

\section{Use of firewood and wood from native forests in communities of the Vilcanota Mountain Range. Cusco}

\author{
Juan E. Gil-Mora ${ }^{1}$ \& Guido V. Huamán-Miranda ${ }^{2}$ \\ ${ }^{1}$ Escuela de Posgrado, Universidad Nacional de San Antonio Abad Cusco, Paraninfo Universitario, \\ Plaza de Armas s/n, Cusco, Perú. \\ ${ }^{2}$ Escuela Profesional de Agronomía, Universidad Nacional de San Antonio Abad Cusco, Centro Agronómico K’ayra, \\ San Jerónimo $s / n$, Cusco, Perú. \\ *Autor corresponsal: Juan E. Gil-Mora, mundoandino2005@yahoo.es
}

\begin{abstract}
RESUMEN
En la cordillera del Vilcanota, la vegetación arbórea y arbustiva leñosa está deteriorada, pero, existen especies usados para satisfacer necesidades de leña, madera para construcción y fabricación de aperos agrícolas y utensilios caseros. Los bosques andinos se encuentran en constante cambio influenciados por el hombre, que provocan variaciones en la composición de la vegetación. El objetivo del presente trabajo es analizar el uso de leña y madera proveniente de bosques nativos comunales, en el empleo como material de construcción para la vivienda, herramientas, aperos agrícolas y utensilios domésticos en forma comparativa del uso actual y de hace 20 años; el diseño de la investigación fue cuasi experimental de tipo corte transversal dirigida a un grupo de control específico, representado por líderes comunales, varones en la actividad de obtención de leña y madera y campesinos que utilizan estos recursos desde hace varias décadas; la encuesta fue aplicada a 40 personas representativas, se formularon 10 preguntas cerradas. En cuanto al uso de leña, todas las especies nativas han disminuido respecto de su uso hace 20 años en más del $60 \%$ y el eucalipto se incrementó en 11 veces; en el uso de las especies para el techado de la vivienda, la única especie nativa que incrementó su uso es el aliso en un $14 \%$ y el eucalipto se incrementó en 4 veces; en el uso de aperos y herramientas, la única especie que incrementó su uso es el eucalipto en más del 70\%, en cambio, las especies nativas, disminuyeron en $80 \%$.
\end{abstract}

Palabras clave: Apero, bosque nativo, dendroenergía, rebrote, reforestación.

\section{ABSTRACT}

In the Vilcanota mountain range, the woody arboreal and shrub vegetation is deteriorated, but there are species used to satisfy the needs of firewood, wood for construction and the manufacture of agricultural implements and homemade utensils. Andean forests are constantly changing influenced by man, causing variations in the composition of the vegetation. The objective of this work is to analyze the use of firewood and wood from communal native forests, in employment as construction material for housing, tools, agricultural implements and domestic utensils in a comparative way of current use and 20 years ago; the research design was quasi-experimental of a cross-sectional type aimed at a specific control group, represented by community leaders, men in the activity of obtaining firewood and wood, and peasants who have used these resources for several decades; the survey was applied to 40 representative people, 10 closed questions were formulated. Regarding the use of firewood, all native species have decreased with respect to their use 20 years ago by more than $60 \%$ and eucalyptus increased by 11 times; in the use of species for the roof of the house, the only native species that increased its use is alder by $14 \%$ and eucalyptus increased by 4 times; in the use of implements and tools, the only species that increased its use is eucalyptus by more than $70 \%$, while native species decreased by $80 \%$.

Key words: Implement, native forest, reforestation, regrowth, wood energy

\section{INTRODUCCIÓN}

Considerando que el recurso forestal en los altos andes constituye un recurso de importancia para las comunidades campesinas asentadas por encima de los $3200 \mathrm{~m}$ de altitud, donde la principal fuente de energía para la cocción de alimentos y calefacción de la vivienda es la biomasa vegetal procedente de los bosques nativos comunales, aunque en los últimos años la leña del eucalipto ha ido cobrando un interés inusitado que viene reemplazando a la leña procedente de los bosques remanentes y aislados que no poseen manejo adecuado.

La región andina, presenta características ambientales muy particulares, en lo que respecta a la precipitación, temperatura, horas sol, etc., factores que han influenciado en el desarrollo de una comunidad vegetal adaptada a estas condiciones, donde la estacionalidad climática, complementada con la altitud limitan el desarrollo de la vegetación, diversificándola; encontrando en ella especies de gran valor sean estas forestales, arbustivas, semi arbustivas y herbáceas; al mismo tiempo es una zona promisoria de recursos principalmente el hídrico; presenta una gran belleza escénica y paisajística, del mismo modo es una zona muy frágil ambientalmente, donde las poblaciones asentadas hacen uso de estos recursos en forma no planificada, debido al incremento de la población, lo que demanda un mayor consumo de leña, productos del bosque, ampliación de la frontera agrícola, así mismo es una zona que está sujeta a problemas de erosión.

A pesar de que la vegetación arbórea y arbustiva leñosa se halla intervenida y por lo tanto deteriorada, existen especies de sumo interés como fuente de energía; estas especies que son las más utilizadas por las comunidades campesinas no superan más allá de 14 especies que a decir de los propios comuneros, constituyen las más importantes desde el punto de vista de la satisfacción de necesidades básicas referentes a leña, madera para construcción y para la fabricación de aperos agrícolas y utensilios caseros. 
La leña, a medida que transcurre el tiempo, es cada vez más escasa en muchas áreas del territorio nacional, especialmente en la zona altoandina; por tanto, las familias van encontrando serias dificultades para abastecerse de leña, motivo por el que muchas veces tienen que desplazarse a grandes distancias, dedicando buena parte de su tiempo a la recolección, restando oportunidad para dedicarse a otras actividades (Muñoz 2008). Las comunidades amazónicas, aunque en proporciones mucho menores, también empiezan a sentir la escasez de la leña producto de la gran intervención humana a los alrededores de los centros poblados; por ello es muy común ver que tanto varones y mujeres que vienen de trabajar de sus chacras retornen con cargas de leña.

\section{Bosques andinos, algunas características}

Los Andes se formaron por actividad tectónica y la vegetación actual se formó en la parte sur durante la última glaciación y fue expandiéndose gradualmente hacia el norte, limitada por ciertas barreras geográficas y climáticas (Morrone, 2001). Los bosques andinos son formaciones de vegetación tropical de altura; tipifican las regiones más elevadas de la franja tropical. Se caracterizan por climas predominantemente secos y fríos. Dadas las características geológicas de los Andes (Morrone, 2001), el clima suele ser agreste y las especies de plantas que crecen en estos ecosistemas se encuentran bien adaptadas a las condiciones climáticas predominantes.

Las formaciones de vegetación de la región andina varían en función a las condiciones ambientales y las barreras naturales, así como por la influencia humana. Son muchas las especies de árboles que crecen en estos bosques, las principales son las del género Polylepis, Escallonia, Hesperomeles, Myrcianthes, Myrcine, Citharexylon, Gynoxys, Buddleja, Vallea y otros que tienen gran importancia ecológica para otros organismos. Estos están adaptados a los climas fríos y secos, aunque su crecimiento es sumamente lento (Cabrera \& Willink, 1973). Los bosques andinos se encuentran en constante cambio debido a las fluctuaciones climáticas y a la explotación y destrucción por parte del hombre.

Los bosques andinos históricamente han sido fuertemente afectados por la actividad humana y lo siguen siendo (Kessler \& Driesch, 1993), puesto que el valor extractivo de las especies es alto, tomando en cuenta las características del lugar y la escasez de recursos. Las actividades extractivas y de sobreexplotación de los bosques andinos están ocasionando daños que pueden tomar cientos o incluso miles de años en volver a un equilibrio natural (Sentir.org, 2001). Los bosques andinos se encuentran gravemente amenazados; en muchas partes permanecen sólo como fragmentos aislados en la parte alta de las montañas y en las laderas más empinadas.

La vegetación de altura se caracteriza por ser fuertemente xerofítica y, la niebla, especialmente en la época de estío, tiene un papel ecológico central puesto que en muchos casos es la única fuente de humedad ambiental (Van Der Hammen \& Cleef, 1986), (Fig. 1).

Las familias de árboles más representativas de la región andina son: rosáceas, ericáceas, melastomatáceas, leguminosas, araliáceas, mirtáceas y podocarpáceas (Morrone, 2001). De acuerdo con Morrone (2001), en la región andina se encuentran los siguientes tipos de bosque:

- Bosque xerofítico: Variable en altitud, pero caracterizado por un régimen de precipitación sumamente seco. Las especies adaptadas a estas condiciones evidencian hojas modificadas, tallos espinosos y forman rodales.
- Bosque montano: Ubicado a altitudes significativas, los árboles son más pequeños, de tallo retorcido y más dispersos (menos asociación), la presencia de epifitas se reduce. Suele dominar Polylepis por estar bien adaptado a un régimen seco y a bajas temperaturas.

- Bosque templado de transición: Entre el bosque templado y el bosque montano, posee elementos similares al bosque templado pero los árboles no alcanzan tanta altura y las asociaciones de individuos son menos gregarias.

- Bosque templado: Tipifica a elevaciones menores, por las mejores condiciones de temperatura y humedad, suele caracterizarse por formaciones boscosas con árboles que suelen alcanzar varios metros de altura y las epifitas tienen una presencia considerable.

En los bosques andinos destaca el género Polylepis. Esta rosácea es un árbol de crecimiento lento que puede alcanzar algunos metros de altura después de varios años, sus troncos son delgados y retorcidos, y poseen una corteza característica que se desprende como papel (Jussieu, 1993). Esta especie y sus parientes cercanos son dominantes en toda la región andina y tienen una gran importancia ecológica, puesto que ofrecen microclimas propicios que determinan la presencia de otras especies de flora, fauna y microorganismos, que de otra manera no podrían estar presentes en esta zona.

Históricamente, desde tiempos precolombinos, los bosques de Polylepis han sido un hábitat muy intervenido y fragmentado (Fjeldsa y Kessler, 2004, Purcell et al. 2004), señalan una pérdida del 70 al $90 \%$ de la cobertura original (Etter y Villa, 2000). Algunas causas son la expansión de la frontera agrícola, las prácticas ganaderas y el uso como combustible doméstico. En consecuencia, es uno de los ecosistemas más afectados (Navarro et al. 2005) y se ha clasificado como un ecosistema con una alta prioridad de conservación.

Adicionalmente, los bosques de Polylepis presentan un patrón biogeográfico insular, dentro de los ecosistemas de puna y páramo (Fjeldsa y Kessler, 2004), estos árboles tienen una extraordinaria adaptación al frío altoandino: su corteza se desprende formando un paquete alrededor del tronco a modo de aislante térmico para protegerlo contra las heladas. Los ejemplares de Polylepis, se caracterizan por formar pequeños bosquetes representativos y constituyen la especie leñosa dominante o exclusiva, a excepción de aquellas especies que habitan los bosques mixtos montanos. Por otro lado, especies como Polypelis pepei, y Polylepis besseri suelen habitar las zonas de transición entre los bosques montanos y zonas nivales y forman pequeños parches cuya distribución se encuentra asociada con laderas y quebradas rocosas y morrénicas ubicadas por encima de los $4600 \mathrm{~m}$. de altitud.

\section{Factores de cambio de los bosques andinos}

El principal factor natural que rige el cambio en los bosques andinos es el clima (Graf, 1994; Villalba, 1995) puesto que los organismos responden de distinta manera (en términos fisiológicos) a las diferentes condiciones de temperatura, humedad y disponibilidad de nutrimentos (Villalba, 1995). En la región de los Andes se observan marcadas diferencias de precipitación anual entre épocas (Graf, 1994), lo cual suele provocar ciertos patrones de cambios cíclicos (Fittkau et al. 1968) en las formaciones boscosas. Otro factor natural de cambio de los bosques andinos son las barreras naturales (Thorson, 1999) puesto que los límites glaciales, que suelen provocar cambios abruptos de vegetación y paisaje, se van moviendo paulatinamente (avanzando y retrocediendo) de acuerdo a los ciclos de calentamiento y enfriamiento, global y regional. 


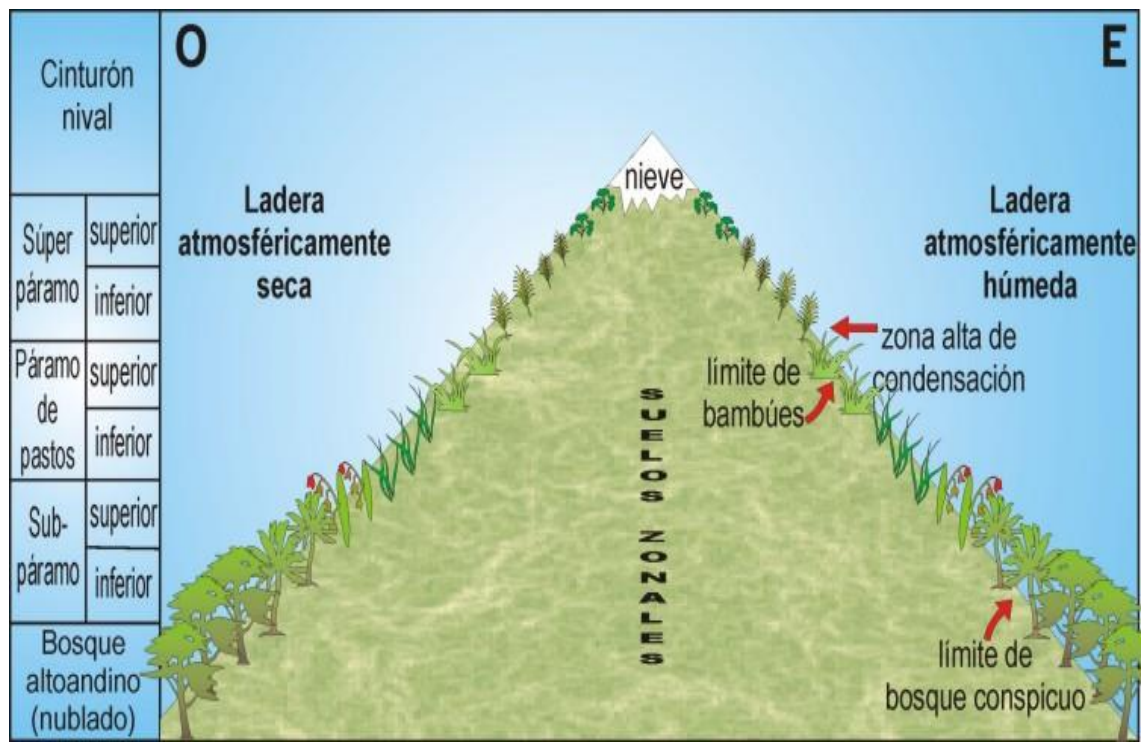

Figura 1. Zonación fisionómica de la cordillera oriental (adaptado de Van Der Hammen \& Cleef, 1986).

El hombre ha ejercido influencia sobre los bosques andinos desde que los primeros asentamientos humanos en la región comenzaron a hacer uso de los recursos de éstos (Kessler \& Driesch, 1993). Si bien las culturas ancestrales se caracterizaron por un gran respeto a la naturaleza y una extracción responsable de los recursos, esta actividad a lo largo de miles de años tuvo impacto (Kessler \& Driesch, 1993). La influencia humana más acentuada se ha registrado en el último siglo, puesto que el avance de la civilización y el crecimiento demográfico ha llevado a los grupos humanos cercanos a los bosques andinos a hacer uso, explotación y sobreexplotación de los recursos naturales (Kessler \& Driesch, 1993), en especial de la madera.

El género Polylepis, representado por varias especies, ha sido el principal afectado,puesto que su madera es extraída para ser usada como leña, para la elaboración de carbón, fabricación de aperos agrícolas, como tintórea y ocasionalmente como soporte de construcción. Las condiciones microclimáticas que ofrecen estos árboles a una amplia diversidad de plantas, animales, hongos y microorganismos son esenciales para su sobre vivencia en un clima tan agreste como el de la alta montaña, y al ser destruidos los árboles toda esta biodiversidad perece con ellos (Kessler \& Driesch, 1993).

La actividad humana también destruye los bosques andinos mediante las quemas sin control, que tienen como único propósito habilitar terrenos para la agricultura. En estas zonas, los fuegos inducidos por el hombre provocan una destrucción masiva de los ecosistemas, los cuales suelen reducir los bosques a praderas (Smithsonian NMNH, 2000).

Los bosques andinos suelen recuperarse en unos cientos de años, cuando solamente se ha dañado la parte arbórea, pero si ha habido un proceso de desmonte por quema (u otro método), la recuperación de los ecosistemas tomaría miles de años, puesto que los suelos de la región son de reciente formación, frágiles y escasos en nutrimentos, y al perder la capa protectora de hojarasca (generada por los árboles) las lluvias, en función a las pendientes, ocasionan fuertes procesos de erosión que incluso pueden llevar a la desertificación de determinadas áreas (Morrone, 2001).

\section{Crisis de leña}

Los recursos forestales han constituido históricamente una importante fuente de energía. Sin embargo, este rol ha sido cada vez más cuestionado a la luz de los impactos ambientales que se producen por su consumo y recolección. Estos cuestionamientos han relegado a un segundo plano el reconocimiento de la capacidad que tienen los bosques nativos de dar soluciones y oportunidades a ciertos segmentos de la población que dependen de ellos, al igual que la posibilidad de que los bosques sean usados en el desarrollo de la comunidad. Es decir, los impactos negativos que puede tener la extracción para leña no deben ocultar el hecho de que esta puede ser usada de manera sustentable y, por lo tanto, proporcionar beneficios ambientales, sociales y económicos. En el estudio previo se llegó a la conclusión de que las comunidades campesinas de la cordillera del Vilcanota consumen $1,754 \mathrm{~kg} /$ persona/día de leña, de los cuales más del $60 \%(1,10)$ del combustible utilizado proviene de los bosques nativos (Gil et al 2020).

La información a nivel mundial señala que alrededor del $50 \%$ de los 3200 millones de toneladas de madera recogida en todo el planeta se quema como combustible. En algunos lugares esta proporción llega a las cuatro quintas partes. Es decir, que un producto con tantas aplicaciones tecnológicas como la madera se acaba convirtiendo en calor, como si no tuviésemos otras fuentes de calor más limpias y renovables (Gehu et al, 1992).

Las mujeres y los niños son los principales recolectores de leña como combustible para cocinar, el cual representa el $80 \%$ de la energía consumida en los hogares de los países en vías de desarrollo (un $40 \%$ en Latinoamérica, un $60 \%$ en África y un $80 \%$ en Asia). Las mujeres dedican entre 1 y 5 horas diarias al suministro de leña (FAO, 2008 a).

Cerca de 2000 millones de personas están afectadas por la denominada crisis de leña. El déficit mundial de leña es de 1 000 millones de metros cúbicos al año. Como término medio, se calcula que el consumo por persona es de unos $225 \mathrm{~kg}$. de leña al año $(0,5 \mathrm{~m} 3)$, pero, esta cifra varía según los países. Las consecuencias de esta presión se traducen en la deforestación de los bosques tropicales, la desertización y erosión de los suelos agrarios, las enfermedades y las alteraciones climáticas (FAO, 2009). El consumo de estos 1 000 millones de $\mathrm{m} 3$ de leña para cocinar produce emisiones en la atmósfera de unos 825 millones de toneladas de dióxido de carbono (el equivalente al $41 \%$ de las emisiones de $\mathrm{CO} 2$ de la Unión Europea: 2000 millones de toneladas por año). El uso y la escasez de leña reflejan, entonces, una relación 
dinámica entre la base de recursos naturales y los sistemas de producción local. Se puede, por ejemplo, contrastar el abastecimiento en localidades rurales, donde la leña es un recurso gratuito, con el de los centros urbanos, donde la leña es una mercancía. Esto último constituye una realidad en los recientes años y posibilita que los comuneros que tienen acceso al bosque obtienen leña y madera para su comercialización en las poblaciones del piso de valle, especialmente en Ollantaytambo, Urubamba, Calca, Pisaq e incluso Lares.

La leña, es una de las fuentes de energía calorífica, usada con mayor antigüedad a nivel mundial, y actualmente persiste en países en vías de desarrollo. En esencia, es la madera bruta seca en trozos normalmente medianos a pequeños, derivados de manera casi directa de los bosques. Generalmente se usa en sistemas de cocción, calefacción, e incluso a partir de este se puede derivar, por ejemplo, a carbón vegetal sin necesidad de realizar transformaciones físico-químicas importantes o de alto costo (FAO, 2007).

En el país las fuentes generadoras de energía renovable son la leña, bosta y yareta (Azorella compacta, una especie fanerógama de la familia Apiaceae que prospera en la puna de Los Andes), bagazo de la caña de azúcar (Saccharum officinarum) después de extraído el jugo, energía solar, carbón vegetal, energía hidráulica y energía eólica (MINEM, 2007). La tabla 1 muestra la producción de energía primaria en el Perú clasificada como no comercial. La leña y la bosta son de uso tradicional en el Perú. Se trata de un uso principalmente doméstico, no comercial (autoconsumo), existiendo un mercado para leña en las ciudades intermedias y pequeñas principalmente. En la actualidad la leña constituye el $20 \%$ de energía primaria consumida en el país. El 77,4\% de la población rural del Perú cocina con leña y el 14,5\% con estiércol o bosta. Aproximadamente 3300000 hogares entre el ámbito urbano y rural dependen de ella (MINAG, 2009).

Tabla 1. Producción de energía primaria en Terajoules (TJ) de energía no comercial.

\begin{tabular}{llll}
\hline \multirow{2}{*}{ Fuente } & \multicolumn{2}{l}{ Reservas probadas (TJ) } & Variación (\%) \\
& $\mathbf{2 0 0 5}$ & $\mathbf{2 0 0 6}$ & \\
\hline Leña & 77227 & 80132 & 3,8 \\
Bagazo & 11929 & 13958 & 17,0 \\
Bosta y yareta & 10368 & 10243 & $-1,2$ \\
Energía solar & 2323 & 2337 & 0,6 \\
Total & $\mathbf{1 0 1 8 4 7}$ & $\mathbf{1 0 6 6 7 0}$ & $\mathbf{4 , 7}$ \\
\hline
\end{tabular}

Fuente: Ministerio de Energía y Minas, 2007.

Según el Censo de Población y Vivienda del año 2007 realizado por el Instituto Nacional de Estadística e Informática (MINAM/INEI/PNUMA, 2009) a nivel nacional el $30,16 \%$ de la población usa leña, mientras que el $2,53 \%$ usa carbón. Los principales departamentos en donde la población utiliza estos combustibles sólidos son Huancavelica $(87,75 \%)$, Apurimac $(84,72 \%)$ y Cajamarca $(78,77 \%)$, coincidentemente todos en la sierra peruana. Entre los departamentos cuya población utiliza menos combustibles sólidos se encuentran Lima (4,75\%), Arequipa $(15,56 \%)$ e Ica $(15,84 \%)$, todos ubicados en la costa (MINAM/INEI/PNUD 2009).
La Corporación de Certificación de Leña (2009) afirma que, a diferencia de las fuentes de energía fósil, la combustión de leña tiene un efecto neutro sobre el balance de dióxido de carbono (C02) en la atmósfera. Es decir, no contribuye al efecto invernadero causante del cambio climático, siempre y cuando provenga de un bosque o plantación manejado en forma sustentable.

Por su parte Bond y Roden (2006), citados por Heising (2006), mencionan que las cocinas que emplean leña o desechos de cosecha como combustible contribuyen al cambio climático mucho más de lo que se pensaba. Ellos han descubierto que el humo generado por el fogón, tradicionalmente utilizados en países en desarrollo para cocinar y para calentar, contiene el doble de partículas de hollín de lo que indican mediciones previas en laboratorio. Estas partículas nocivas y negras (más oscuras que aquellas producidas por la quema de pastizales o los incendios forestales), absorben gran cantidad de luz solar y contribuyen así a aumentar la temperatura del planeta al ser liberadas a la atmósfera. La FAO (2006), afirma que, si se produce el combustible de madera de forma insostenible talando bosques, la sustitución de combustibles fósiles por dendroenergía no ejercerá un efecto positivo en los balances del carbono y podría incluso ser peor que el uso de combustibles fósiles.

Respecto del empleo de la biomasa vegetal como combustible el INEI (2005), especifica lo anotado en la Tabla 2.

Tabla 2. Uso de Biomasa como Combustible en el Perú.

\begin{tabular}{ll}
\hline Ámbito & $\mathbf{\%}$ \\
\hline Lima Metropolitana & $3,66 \%$ \\
Selva Rural & $95,54 \%$ \\
Selva Urbana & $61,82 \%$ \\
Sierra Rural & $76,22 \%$ \\
Sierra Urbana & $45,00 \%$ \\
Costa Rural & $87,96 \%$ \\
Costa Urbana & $31,77 \%$ \\
Total Urbana & $\mathbf{2 5 , 9 2 \%}$ \\
Total Rural & $\mathbf{8 2 , 0 5 \%}$ \\
Total & $\mathbf{4 2 , 9 7 \%}$ \\
\hline
\end{tabular}

Fuente: INEI, 2005

La tabla precedente indica que, exceptuando Lima metropolitana, más del $80 \%$ de la población del país utiliza como fuente de energía la biomasa vegetal, especialmente en la zona rural; por lo tanto, existe la gran necesidad de acometer programas regionales de reforestación a efecto de incrementar la oferta de leña desde los bosques manejados, uso de cocinas mejoradas y otros implementos a efecto de disminuir el consumo o demanda de leña $y$, acometer programas de información y capacitación en el uso apropiado de la leña.

La FAO, (2008b) determina una escala de combustibles desde lo más contaminante a lo menos contaminante; especificando lo siguiente:

- Icchu o paja

- Bosta, estiércol

- Residuos agrícolas 
- Leña

- Carbón vegetal

- Kerosene, aceite vegetal

- Gas, ethanol

- Energía eléctrica

Si bien es cierto que la leña ocupa una posición intermedia en la escala precedente y aun cuando se podría disminuir sus niveles de contaminación a través del secado, la gran ventaja que posee está referida al costo respecto a los otros combustibles más limpios. Esta ventaja es de sumo interés para las comunidades campesinas, pues la leña, representa un bien "gratuito" o un bien de bajo costo, de obtención relativamente fácil. Los recursos forestales han constituido desde siempre una fuente importante de energía para la humanidad. Sin embargo, en la actualidad su utilización es frecuentemente cuestionada por el impacto ocasionado sobre el ambiente, sin considerar que también son fuente de soluciones y oportunidades para un importante segmento de la población urbana y rural.

El objetivo del presente trabajo es analizar el uso de leña y madera proveniente de bosques nativos comunales, tanto en el empleo como material de construcción para la vivienda, herramientas, aperos agrícolas y utensilios domésticos en forma comparativa del uso por los comuneros hoy en día y hace 20 años; igualmente es objetivo del trabajo, el estudio de las características más importantes de las especies nativas como es el caso de la capacidad de rebrote, tolerancia a temperaturas extremas y la aridez.

\section{Ámbito de estudio}

El ámbito de estudio se halla en la Cordillera del Vilcanota, localizada en el departamento del Cusco el que es un componente de la cadena oriental de los Andes del Perú, se ha considerado como parte de la muestra para el estudio a ocho comunidades representativas: Phallata, Willoq y Patacancha en la microcuenca del río Patacancha en el distrito de Ollantaytambo y cinco comunidades en el distrito de Lares microcuenca de los ríos Lares y Trapiche: Pampacorral, Kiswarani, Wakawasi, Kunkani y Tambowaylla; todas ubicadas por encima de los 3200 m.s.n.m (Fig. 2).

Las comunidades campesinas se ubican en las zonas denominadas cabecera de cuenca donde la cobertura vegetal arbustiva, semiarbustiva y herbácea viene siendo deteriorada por efecto de la intervención del hombre, debido a acciones de sobre explotación, sobre pastoreo e incendios forestales; actividades que influyen directamente en la perdida inevitable del recurso hídrico en razón de que se rompe parte del ciclo hidrológico, se deterioran los suelos por efecto de la erosión; una de estas acciones es la tala de los árboles nativos con la finalidad de satisfacer la demanda energética de las poblaciones; ante esta problemática instituciones gubernamentales y no gubernamentales vienen desarrollando un conjunto de actividades a fin de reducir los impactos generados por estas acciones, una de estas instituciones es ECOAN, que desarrolla trabajos tendientes a reducir el consumo de leña y ampliar las áreas forestales con este fin y proteger la vegetación natural de la cabecera de cuenca por la gran diversidad de especies vegetales y animales que alberga.

La topografía del ámbito de estudio, es completamente irregular y en las partes medias y altas se encuentran formaciones boscosas de Escallonia (chachacomo, t'asta), Hesperomeles (lenle, mayu manzana), Vallea (chiqllurmay), Duranta (mot'e mot'e), Kageneckia (lloque), Myrcianthes (unca), Cytharexylum (k'uruchu), y Polylepis (queñua); estas especies forman bosques mixtos o monoespecíficos de distribución restringida, por lo tanto representan ecosistemas y hábitats de interés ecológico, climático y biogeográfico. Sin embargo, y a pesar de su importancia biológica, estos bosques, representan uno de los hábitats más vulnerables de los altos Andes, por la creciente presión humana debido a factores económicos, sociales, y culturales

\section{MÉTODO}

El diseño de la investigación fue cuasi experimental de tipo corte transversal porque la investigación fue dirigida a un grupo de control específico, y tiene una perspectiva metodológica cualitativa y cuantitativa, es decir mixta. Sin embargo, cabe resaltar que se pretende conocer más sobre el uso de la vegetación proveniente de bosques altoandinos nativos remanentes; el público objetivo definido para la obtención de la información estuvo integrado por líderes comunales, varones en actividad de obtener leña y madera para los usos en la vivienda y el trabajo en la finca.

Según el tipo de información recopilada y generada, la investigación es cualitativa, puesto que se analizan los principales usos de la madera y leña utilizados en las comunidades altoandinas ubicadas en el ámbito de estudio y sus impactos en el bosque y el ambiente. Desde la perspectiva de la técnica de investigación, el presente trabajo constituye, además, una investigación documental, pues hace posible el procesamiento de información obtenida en base de datos e información de carácter secundario (Sánchez, 2019).

El grupo de control específico estuvo representado por líderes comunales, varones en la actividad de obtención de leña y madera y campesinos que utilizan estos recursos desde hace varias décadas; en tal sentido, la encuesta fue aplicada a 40 personas representativas. Se formularon 10 preguntas al grupo de control en base al conocimiento y al análisis crítico del tema de investigación, con el fin de conocer la percepción que tienen del uso de los bosques comunales y la leña y madera obtenidas para sus diversas actividades, tanto en la vivienda como en la finca.

El cuestionario fue diseñado con el objetivo de obtener información sobre la opinión y propuestas de los líderes comunales y campesinos en actitud de obtener leña y madera. Además, se consideró una presentación neutral de las preguntas para evitar introducir sesgos debido a que estos obstaculizan la determinación de la verdadera opinión de los encuestados (Casas Anguita et al, 2002). La encuesta fue aplicada en un periodo de tres meses; una vez obtenidos los resultados, se inició el procesamiento de dicha información.

Para la estimación de la tasa de crecimiento poblacional, se utilizó la metodología propuesta por el INEI (2009) y se empleó los padrones comunales proporcionados por los líderes de las comunidades campesinas; se aplicó una estimación con proyección a corto plazo, aquella que se realiza para períodos inferiores a 5 años; utilizándose la siguiente ecuación:

$$
N_{t}=N_{0}(1+r) t
$$

Donde:

No $=$ Población de inicio.

$\mathrm{Nt}=$ Población al final del periodo.

$\mathrm{t}=$ Tiempo en años entre No $\mathrm{y} \mathrm{Nt}$

$\mathrm{r}=$ Tasa de crecimiento.

Despejando r para hallar la tasa de crecimiento, se tiene:

$r=\left(\frac{N_{t}}{N_{0}}\right)^{\frac{1}{t}}-1$ 


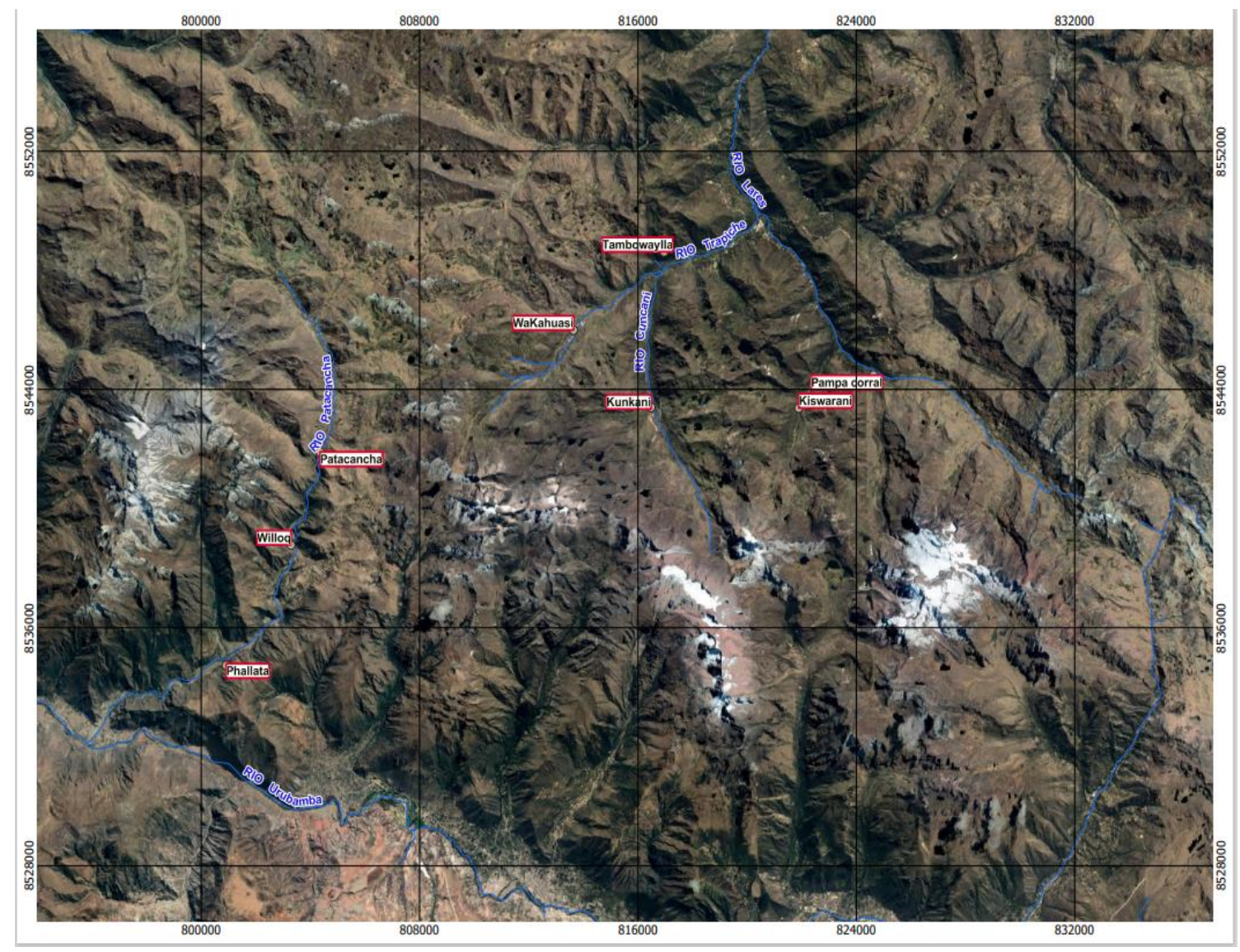

Figura 2. Ámbito de estudio

Fuente. Base cartográfica Google Earth Pro

\section{RESULTADOS}

La población, número de familias y su respectiva proyección en las comunidades campesinas de los distritos de Ollantaytambo y Lares se muestra en la Tabla 3.

La información que proporcionan la tabla 3 , revela que las comunidades campesinas próximas a centros urbanos tienen las más altas tasas de crecimiento, así se observa en las comunidades campesinas localizadas en el distrito de Ollantaytambo, concretamente con la comunidad campesina de Phallata, que dista pocos kilómetros de Ollantaytambo, considerando que esta localidad, a su vez, comprende el espacio arqueológico de Ollantaytambo, que es un centro poblado que viene desarrollándose urbanísticamente debido al flujo turístico receptivo, hecho que influye en las actividades económicas y laborales de las comunidades campesinas; es decir, tiene un efecto gravitatorio espacial muy fuerte, manifestándose concretamente en el precio del trabajo comunal que se mide por jornal equivalente a ocho horas de trabajo al día, fenómeno que está iniciándose en las comunidades campesinas localizadas en el distrito de Lares por el dinamismo del turismo de aventura y vivencial que se está desarrollando en este espacio y por tanto ya está manifestándose en el precio del trabajo comunal.

Teniendo las tasas de crecimiento poblacional se calcula la proyección de la población comunal para un horizonte de cinco años, proyección que si bien muestra que la población comunal casi permanece estacionaria; sin embargo, en el futuro se verá incrementada debido al desarrollo de las actividades económicas dedicadas al turismo, lo que a su vez determinará una tendencia a crecer y exigirá una mayor permanencia en los espacios comunales, actualmente esta población comunal para proveerse de recursos monetarios migra a otros espacios económicos donde encuentran trabajo como es en el valle de la provincia de La Convención, fundamentalmente en los meses de cosecha de café; esta tendencia de la población de las comunidades campesinas a ser más estacionaria, a su vez exigirá mayor consumo de leña para preparar sus alimentos e interactuar socialmente debido a sus factores culturales, como fiestas patronales, ceremonias religiosas, etc. aspecto que exige necesariamente un programa de reforestación, dado que otras alternativas o cambios en las matrices energéticas exigirían un programa educativo a mediano plazo sin asegurar que pueda tener éxito por la resistencia del campesino alto andino a cambiar sus patrones culturales en la preparación de sus alimentos.

La principal actividad productiva de la zona es la agricultura. En la parte baja predominan los cultivos de maíz, alfalfa, cebada, trigo y papa. En la parte alta, caracterizada por la presencia de bosques naturales, arbustos y matorrales, se cultiva papa, haba, arveja, olluco, cebada y tarwi. A los sistemas de producción agrícola se suman la crianza de vacunos, ovinos, caprinos, algunos equinos, porcinos, cuyes, aves de corral y otros.

\section{Leña y principales usos energéticos}

La combustión de leña proporciona energía calórica, la cantidad de energía que ofrece la leña, dependerá de la densidad de la madera, del contenido de humedad y de la cantidad de leña adquirida. La leña recién obtenida del bosque tiene una humedad entre 60 y $65 \%$ y su combustión generará sólo la mitad del calor que, si estuviera seca, la otra mitad del calor se gasta en evaporación. La leña que está almacenada secándose y ventilándose por al menos cuatro semanas, posee 
Tabla 3. Población estimada en comunidades campesinas de Ollantaytambo y Lares.

\begin{tabular}{|c|c|c|c|c|c|c|c|c|}
\hline Distrito & 2005 & 2007 & $\begin{array}{c}\text { Tasa crecimiento } \\
\text { Anual } \%\end{array}$ & 2008 & 2009 & 2010 & 2011 & 2012 \\
\hline \multicolumn{9}{|l|}{ Ollantaytambo } \\
\hline \multicolumn{9}{|l|}{ Comunidad } \\
\hline Willoq & 1095 & 1100 & 0,15 & 1102 & 1103 & 1105 & 1107 & 1108 \\
\hline $\begin{array}{l}\text { Phallata } \\
\text { Total Ollantaytambo }\end{array}$ & $\begin{array}{c}260 \\
1355\end{array}$ & $\begin{array}{c}300 \\
1400\end{array}$ & 4,88 & $\begin{array}{c}315 \\
1417\end{array}$ & $\begin{array}{c}330 \\
1433\end{array}$ & $\begin{array}{c}346 \\
1451\end{array}$ & $\begin{array}{c}363 \\
1470\end{array}$ & $\begin{array}{c}381 \\
1489\end{array}$ \\
\hline \multicolumn{9}{|l|}{ Lares } \\
\hline \multicolumn{9}{|l|}{ Comunidad } \\
\hline Tambowaylla & 320 & 325 & 0,51 & 327 & 328 & 330 & 331 & 333 \\
\hline Pampacorral & 350 & 360 & 0,94 & 363 & 366 & 370 & 373 & 377 \\
\hline Kiswarani & 265 & 275 & 1,24 & 278 & 282 & 285 & 289 & 292 \\
\hline Total Lares & 935 & 960 & & 968 & 976 & 985 & 993 & 1002 \\
\hline TOTAL & 2290 & 2360 & & 2385 & 2409 & 2436 & 2463 & 2491 \\
\hline
\end{tabular}

Fuente: Elaborado en base a padrones comunales.

un contenido de humedad inferior a $25 \%$, esto permite duplicar su rendimiento, contaminar menos y ahorrar tiempo y dinero (Suárez, 2014).

Las especies mejor consideradas por su poder calorífico y poca producción de humo en su combustión son: chachacomo, queuña, t'asta, unca, k'uruchu, lloque, lenle, aliso, entre la vegetación arbórea y waka asta, llaulli e incluso la retama, entre los arbustos, según las entrevistas realizadas. Se observa una disminución en el empleo de estas especies para este fin, coherente con una disminución del recurso arbolado nativo y un mayor empleo del eucalipto. Además, el chachacomo, t'asta, unca, qolle, aliso, chiqllurmay y queuña son maderas apreciadas para la construcción de infraestructuras y herramientas, por lo que se han visto enfrentadas a la presión de la venta de su madera a lo largo de los años. Aunque el empleo de la madera de eucalipto como leña existe en la actualidad, lo que no ocurría hace años, no es muy importante frente a otras especies como el aliso. Esto habría que tenerlo en cuenta en posibles programas de reforestación con fines energéticos. El número de especies utilizadas como leña ha disminuido con los años dentro del proceso de deterioro paulatino del bosque y matorral nativo.

Para alcanzar el uso eficiente de la leña sin la emisión de contaminantes, se deben lograr tres condiciones: una leña de calidad con un bajo contenido de humedad, hornillos que posibiliten una buena combustión, y un consumidor responsable e informado. Usualmente se recomienda quemar leña con 12 al 20\% de humedad. La capacidad energética de la leña disminuye considerablemente con el contenido de humedad. Lo anterior implica que existe un factor importante a ser considerado en el uso de la leña como combustible en cuanto a su uso directo; es decir, que será imprescindible que la biomasa vegetal sea almacenada en un lugar seco y ventilado a efecto de que pierda humedad en por lo menos en un $60 \%$, esto implica un almacenamiento de hasta cuatro semanas antes de su uso.

Según el análisis de las entrevistas realizadas, las especies señaladas en el acápite anterior son las más utilizados en razón a sus bondades en el rápido secado, arder mejor y generar una brasa con mayor durabilidad en el proceso de cocción y producir carbón; igualmente ciertas especies nativas como el aliso, chachacomo, queuña y unca son maderas apreciadas para la construcción de infraestructuras y herramientas. El número de especies utilizadas como leña ha disminuido con los años dentro del proceso de deterioro paulatino del bosque y matorral nativo

Como se aprecia en la tabla 4, el empleo de leña proveniente de bosques nativos ha disminuido en forma apreciable, especialmente en especies como queuña, chachacomo, unca, qolle, t'asta, cuyo consumo ha disminuido e incrementado el empleo de la leña de eucalipto en más de 11 veces. Significando ello que la biomasa vegetal es cada vez menor y la demanda de leña es mayor aun cuando el consumo per cápita puede ser similar desde hace 20 años.

\section{Madera y otros usos en la comunidad \\ Techado de la vivienda}

El material utilizado para el techado de la vivienda es uno de los elementos que más cambio ha sufrido. El empleo del denominado "enchaclado" formado sea por palos delgados como el mot'e mot'e, llaulli, aliso, chiqllurmay, carrizo y otros, ha perdido importancia y el eucalipto cobra un uso cada vez más prioritario. El empleo de la calamina necesita de palos largos y rectos, característica del eucalipto. Anteriormente se empleó mucho el aliso y otras especies adecuadas. La diversidad de especies usadas hace años refleja que no se requerían unas características muy específicas para la paja, que era la cobertura principal de las viviendas (Tabla 5).

La información anterior permite colegir que es una necesidad de las comunidades campesinas el contar con especies que posibiliten satisfacer los requerimientos para la construcción de la vivienda, principalmente referente al techado; esto conduce a planificar programas de reforestación con especies que hace algunas décadas empleaban con éxito para estos menesteres.

\section{Herramientas y aperos}

El empleo de Chachacomo, unca, t'asta, aliso, k'uruchu, qolle, chiqllurmay, lenle, lloque y queuña para la construcción de herramientas es absolutamente preferencial. Se construyen o adecuan mangos de utensilios de cocina, herramientas agrícolas, yugo, arados, etc. En otros tiempos, el uso de estas especies era importante, actualmente lo sigue 
siendo aun cuando la proporción ha disminuido sustancialmente a pesar de que las especies se hallan en menor abundancia; sin embargo, existe alta preferencia. Por lo tanto, se puede colegir, que la preferencia por la madera nativa para la fabricación de aperos y utilería es mucho más marcada que para otras cosas, como por ejemplo la leña. La madera de chachacomo, t'asta, unca y aliso son muy importantes como combustible, pero es prioritario su empleo para herramientas. El aliso es apreciado por su fácil trabajo (Tablas 6 y 7).

De las 43 especies estudiadas, 14 especies ofertan madera y leña de calidad; 32 especies poseen una capacidad de rebrote que permite su manejo óptimo; 34 especies pueden soportan fríos extremos y aridez extrema; por lo tanto, son especies adaptadas a esas condiciones de clima y consecuentemente, son óptimas para la reforestación (Tabla $8)$.

Tabla 4. Fluctuación de especies utilizadas como leña (expresado en porcentaje).

\begin{tabular}{lllll}
\hline Especie & Nombre local & Ahora & Hace 20 años & Fluctuación (\%) \\
\hline Allnus acuminata & Aliso & 34,36 & 41,63 & $-17,5$ \\
Escallonia resinosa & Chachacomo & 14,65 & 28,34 & $-48,3$ \\
Vallea stipularis & Chiqllurmay & 12,18 & 25,42 & $-52,1$ \\
Polypelis incana & Queuña & 08,47 & 22,34 & $-62,1$ \\
Myrcianthes oreophilla & Unca & 06,34 & 18,36 & $-65,5$ \\
Kageneckia lanceotata & Lloque & 08,38 & 22,45 & $-62,7$ \\
Gynoxys longifolia & Q'oto kiswar & 04,24 & 18,45 & $-77,0$ \\
Buddleja coriacea & Q'olle & 07,23 & 12,45 & $-41,9$ \\
Hesperomeles latifolia & Lenle & 08,48 & 15,22 & $-44,3$ \\
Citharexylon argutedentatum & K'uruchu & 04,24 & 11,12 & $-61,9$ \\
Senna birrostris & Mutuy & 06,45 & 12,56 & $-48,7$ \\
Escallonia myrtilloides & T'asta & 04,46 & 14,36 & $-68,9$ \\
Barnadesia berberoides & Llaulli & 12,48 & 35,44 & $-64,8$ \\
Eucaliptus globulus & Eucalipto & 48,24 & 04,24 & $1037,7(*)$ \\
\hline Fute. Resultion
\end{tabular}

Fuente. Resultado de entrevistas de campo a líderes comunales.

(*) Es la única especie que incrementó su uso en un elevado porcentaje.

Tabla 5. Fluctuación de especies utilizadas en la construcción del techado de la vivienda (expresado en porcentaje).

\begin{tabular}{llll}
\hline Especie & Ahora & Hace 20 años & Fluctuación $(\%)$ \\
\hline Aliso & 21,08 & $\mathbf{1 8 , 4 4}$ & $\mathbf{1 4 . 3}(*)$ \\
Chachacomo & $\mathbf{0 1 , 4 4}$ & $\mathbf{1 2 , 2 4}$ & $\mathbf{- 8 8 . 2}$ \\
Chiqllurmay & $\mathbf{0 8 , 8 2}$ & $\mathbf{1 8 , 2 2}$ & $-\mathbf{5 1 , 6}$ \\
Queuña & $\mathbf{0 1 , 2 7}$ & $\mathbf{2 1 , 2 4}$ & $-\mathbf{9 4 , 0}$ \\
Unca & $\mathbf{0 2 , 2 3}$ & $\mathbf{1 2 , 1 3}$ & $-\mathbf{8 1 , 6}$ \\
Mot'e mot'e & $\mathbf{1 2 , 4 4}$ & $\mathbf{2 0 , 1 2}$ & $-\mathbf{3 8 , 2}$ \\
Q'oto kiswar & $\mathbf{0 2 , 1 4}$ & $\mathbf{1 0 , 4 5}$ & $-\mathbf{7 9 , 5}$ \\
Q'olle & $\mathbf{0 6 , 2 2}$ & $\mathbf{1 1 , 1 5}$ & $-\mathbf{4 4 , 2}$ \\
Lenle & $\mathbf{0 4 , 2 8}$ & $\mathbf{1 2 , 3 2}$ & $-\mathbf{6 5 , 3}$ \\
Kuruchu & $\mathbf{0 2 , 1 4}$ & $\mathbf{1 6 , 2 2}$ & $\mathbf{- 8 6 , 8}$ \\
T'asta & $\mathbf{0 4 , 6 6}$ & $\mathbf{1 2 , 2 6}$ & $-\mathbf{6 2 , 0}$ \\
Llaulli & $\mathbf{1 0 , 2 8}$ & $\mathbf{2 5 , 1 4}$ & $-\mathbf{5 9 , 1}$ \\
Eucalipto & $\mathbf{9 5 , 3 4}$ & $\mathbf{2 4 , 1 4}$ & $\mathbf{2 9 5 , 0}(*)$ \\
\hline Fuente Resultado de entrevistas de campo a líderes comunales.
\end{tabular}

Fuente. Resultado de entrevistas de campo a líderes comunales.

(*) Son las únicas especies que han incrementado en el empleo para la construcción de la vivienda. 
Tabla 6. Fluctuación de especies utilizadas como herramientas: Yugo, arado, mangos, aperos agrícolas y utensilios de cocina (expresado en porcentaje).

\begin{tabular}{llll}
\hline Especie & Ahora & Hace 20 años & Fluctuación $(\%)$ \\
\hline Aliso & 06,40 & 12,41 & $-48,4$ \\
Chachacomo & 16,14 & 58,54 & $-72,4$ \\
Chiqllurmay & 02,12 & 15,23 & $-86,1$ \\
Queuña & 1.72 & 20,24 & $-91,5$ \\
Unca & 04,24 & 18,46 & -77 \\
Lloque & 1.28 & 08,25 & $-84,5$ \\
Q'olle & 11,83 & 15,35 & $-23,0$ \\
Lenle & 02,28 & 11,42 & -80 \\
Kuruchu & 02,34 & 10,14 & $-76,9$ \\
T'asta & 04,26 & 16,46 & -74.1 \\
Eucalipto & 18,34 & 10,64 & $72.4(*)$ \\
\hline
\end{tabular}

Fuente. Resultado de entrevistas de campo a líderes comunales.

(*) Es la única especie cuyo uso se incrementó en esa proporción.
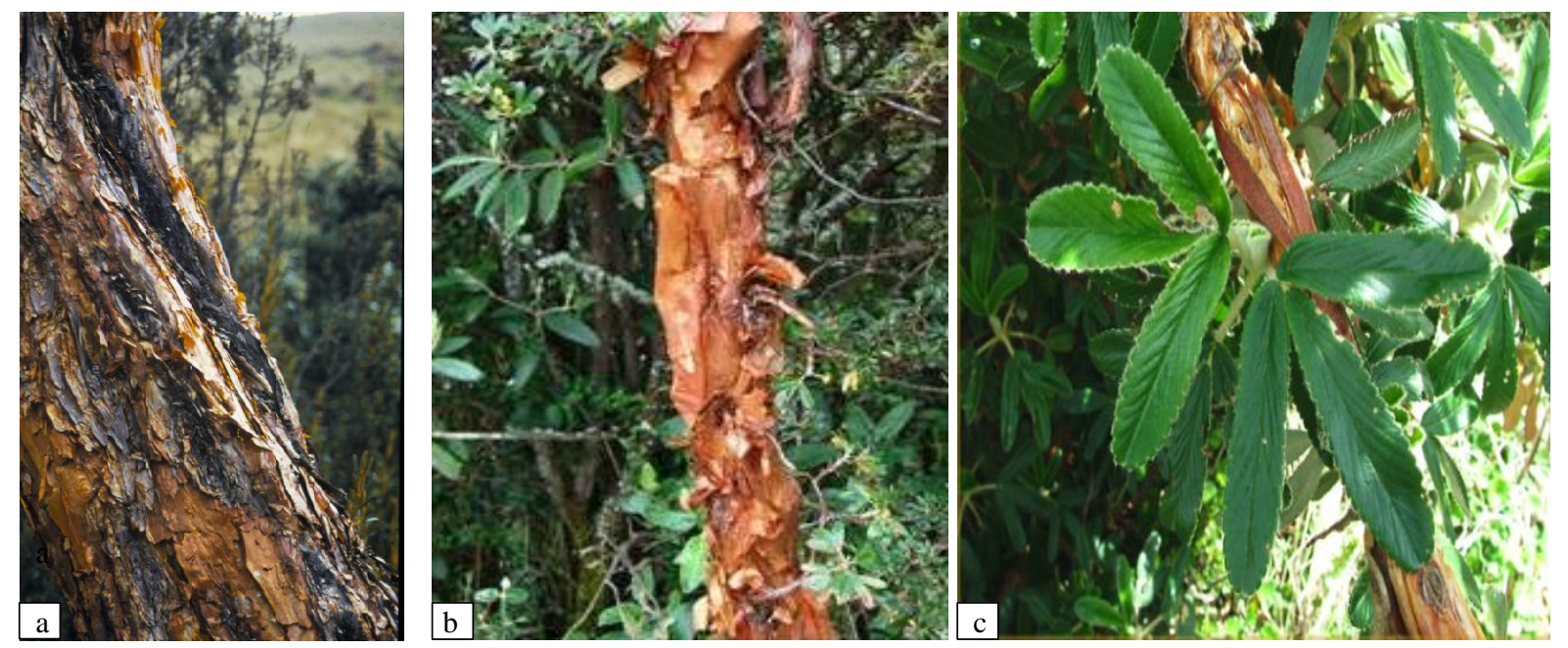

Figuras 3A-C. Diversas especies de Polylepis son las predominantes en los altos Andes.
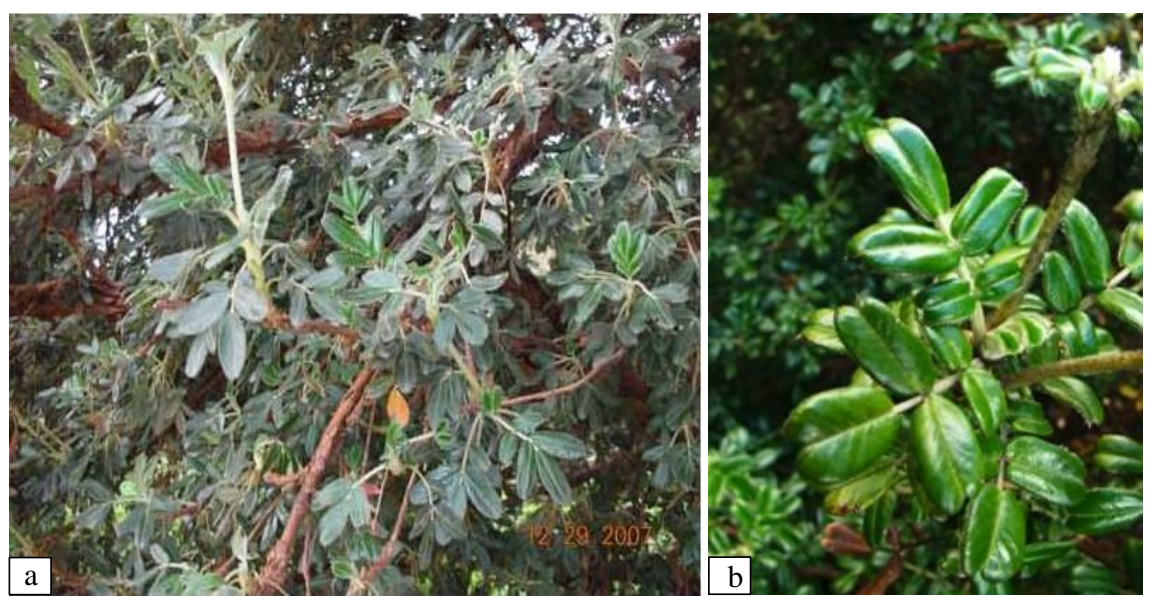

Figuras 4A-B. Las especies del género Polylepis constituyen bosques monoespecíficos en los altos Andes. 
Tabla 7. Características Importantes de las Especies Nativas en la Zona Alto Andina.

\begin{tabular}{|c|c|c|c|c|c|c|c|c|}
\hline Especie & Nombre local & $\begin{array}{l}\text { Madera de } \\
\text { calidad y } \\
\text { buena } \\
\text { dimension }\end{array}$ & $\begin{array}{l}\text { Leña y } \\
\text { carbón de } \\
\text { alto poder } \\
\text { calorífico }\end{array}$ & $\begin{array}{l}\text { Aptas } \\
\text { para } \\
\text { manejo } \\
\text { de } \\
\text { rebrotes }\end{array}$ & Tánicas & Tintóreas & $\begin{array}{l}\text { Toleran } \\
\text { intenso } \\
\text { frío y } \\
\text { extrema } \\
\text { altitud }\end{array}$ & $\begin{array}{c}\text { Toleran aridez } \\
(-400 \mathrm{~mm} \text { de } \\
\text { precipitacion })\end{array}$ \\
\hline Buddleja coriacea & Qolle & & $\mathbf{X}$ & $\mathbf{X}$ & & & $\mathbf{X}$ & \\
\hline Buddleja incana & Kiswar & & $\mathbf{X}$ & $\mathbf{X}$ & & & & \\
\hline $\begin{array}{l}\text { Escallonia } \\
\text { myrtilloides }\end{array}$ & T'asta & $\mathbf{X}$ & $\mathbf{X}$ & $\mathbf{X}$ & & $\mathbf{X}$ & $\mathbf{X}$ & \\
\hline Escallonia resinosa & $\begin{array}{l}\text { Chacha } \\
\text { como }\end{array}$ & $\mathbf{X}$ & $\mathbf{X}$ & $\mathbf{X}$ & & $\mathbf{X}$ & & $\mathbf{X}$ \\
\hline $\begin{array}{l}\text { Myrcianthes } \\
\text { oreophilla }\end{array}$ & Unca & $\mathbf{X}$ & $\mathbf{X}$ & $\mathbf{X}$ & & & & \\
\hline $\begin{array}{l}\text { Hesperomeles } \\
\text { lanuginosa }\end{array}$ & Manzanito & $\mathbf{X}$ & $\mathbf{X}$ & $\mathbf{X}$ & & & & \\
\hline $\begin{array}{l}\text { Hesperomeles } \\
\text { latifolia }\end{array}$ & Lenle & $\mathbf{X}$ & $\mathbf{X}$ & $\mathbf{X}$ & & & & \\
\hline Polylepis racemosa & Queuña & $\mathbf{X}$ & $\mathbf{X}$ & $\mathbf{X}$ & & $\mathbf{X}$ & $\mathbf{X}$ & \\
\hline Polypelis incana & Queuña & $\mathbf{X}$ & $\mathbf{X}$ & $\mathbf{X}$ & & $\mathbf{X}$ & $\mathbf{X}$ & \\
\hline Polylepis subsericans & Queuña & $\mathbf{X}$ & $\mathbf{X}$ & $\mathbf{X}$ & & $\mathbf{X}$ & $\mathbf{X}$ & \\
\hline Polylepis microphylla & Queuña & & $\mathbf{X}$ & $\mathbf{X}$ & & $\mathbf{X}$ & $\mathbf{X}$ & \\
\hline Polylepis pepei & Queuña & & $\mathbf{X}$ & $\mathbf{X}$ & & $\mathbf{X}$ & $\mathbf{X}$ & \\
\hline Sambucus peruviana & Sauco & $\mathbf{X}$ & & $\mathbf{X}$ & & & & \\
\hline $\begin{array}{l}\text { Citharexylon } \\
\text { argutedentatum }\end{array}$ & K'uruchu & $\mathbf{X}$ & $\mathbf{X}$ & $\mathbf{X}$ & & & $\mathbf{X}$ & $\mathbf{X}$ \\
\hline Colletia spinosissima & Roque & & $\mathbf{X}$ & $\mathbf{X}$ & & $\mathbf{X}$ & & $\mathbf{X}$ \\
\hline Gynoxys longifolia & Q'oto kiswar & & $\mathbf{X}$ & $\mathbf{X}$ & & & $\mathbf{X}$ & $\mathbf{X}$ \\
\hline Gynoxys nitida & T'oqorway & $\mathbf{X}$ & $\mathbf{X}$ & $\mathbf{X}$ & & & $\mathbf{X}$ & \\
\hline $\begin{array}{l}\text { Gynoxys } \\
\text { callacatensis }\end{array}$ & Q'oto kiswar & & $\mathbf{X}$ & $\mathbf{X}$ & & & $\mathbf{X}$ & $\mathbf{X}$ \\
\hline $\begin{array}{l}\text { Kageneckia } \\
\text { lanceotata }\end{array}$ & Lloque & & $\mathbf{X}$ & $\mathbf{X}$ & $\mathbf{X}$ & & & $\mathbf{X}$ \\
\hline Myrica pubescens & Laurel de puna & $\mathbf{X}$ & $\mathbf{X}$ & & & & & $\mathbf{X}$ \\
\hline Berberis carinata & Monte cheqche & & $\mathbf{X}$ & $\mathbf{X}$ & & & $\mathbf{X}$ & $\mathbf{X}$ \\
\hline Berberis commutata & Waka asta & & $\mathbf{X}$ & & & $\mathbf{X}$ & & $\mathbf{X}$ \\
\hline Barnadesia horrida & Llaulli & & $\mathbf{X}$ & $\mathbf{X}$ & & & & $\mathbf{X}$ \\
\hline $\begin{array}{l}\text { Barnadesia } \\
\text { berberoides }\end{array}$ & Llaulli & & & $\mathbf{X}$ & & & & $\mathbf{X}$ \\
\hline $\begin{array}{l}\text { Dasyphyllum } \\
\text { leiocephalum }\end{array}$ & T'ancar llaulli & & $\mathbf{X}$ & & & & & $\mathbf{X}$ \\
\hline Lycianthes lycioides & T'ankar quiska & & & & & & & $\mathbf{X}$ \\
\hline Duranta mandonii & Mot'e mot'e & & $\mathbf{X}$ & & & & & $\mathbf{X}$ \\
\hline Vallea stipularis & Chiqllurmay & $\mathbf{X}$ & $\mathbf{X}$ & $\mathbf{X}$ & & & & $\mathbf{X}$ \\
\hline Caesalpinia spinosa & Tara & & $\mathbf{X}$ & $\mathbf{X}$ & $\mathbf{X}$ & $\mathbf{X}$ & & $\mathbf{X}$ \\
\hline Cantua buxifolia & Cantuta & & & $\mathbf{X}$ & & & & $\mathbf{X}$ \\
\hline Senna birrostris & Mutuy & & & $\mathbf{X}$ & & & $\mathbf{X}$ & $\mathbf{X}$ \\
\hline Erythrina edulis & Pisonay & & & $\mathbf{X}$ & & & & \\
\hline Prunus serotina & Capulí & & & $\mathbf{X}$ & & & & \\
\hline Tecoma sambucifolia & Waranway & & $\mathbf{X}$ & $\mathbf{X}$ & & & & $\mathbf{X}$ \\
\hline Baccharis latifolia & Chilca & & & & & $\mathbf{X}$ & $\mathbf{X}$ & $\mathbf{X}$ \\
\hline
\end{tabular}




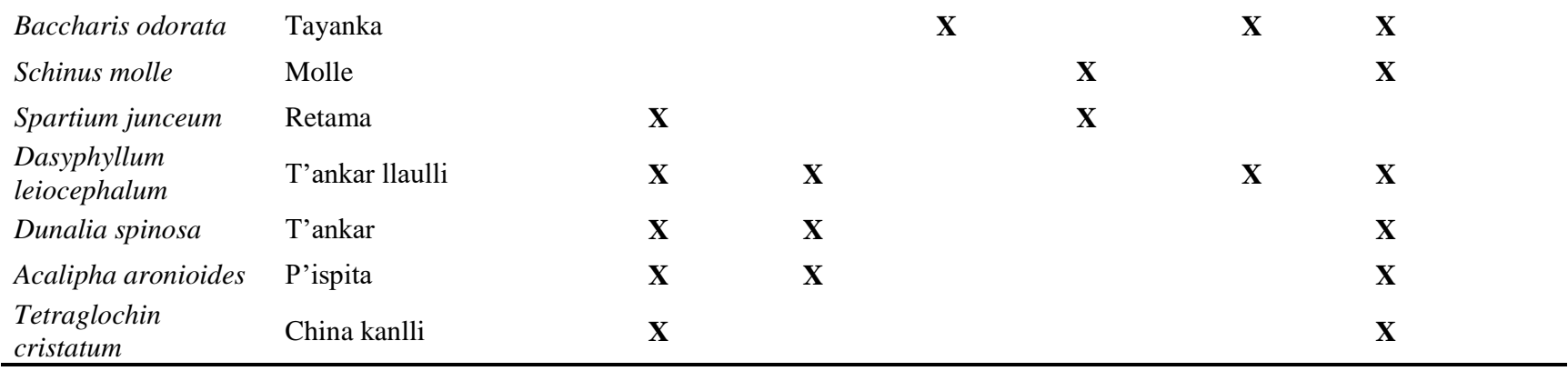

Fuente. Información recogida mediante observaciones y encuestas de campo.

Tabla 8. Especies según Capacidad de Rebrote.

\begin{tabular}{|c|c|c|c|c|}
\hline Especie & Nombre local & $\begin{array}{l}\text { MUY } \\
\text { ALTA }\end{array}$ & ALTA & MODERADA \\
\hline Buddleja coriacea & Qolle & $X$ & & \\
\hline Buddleja incana & Kiswar & $\mathrm{X}$ & & \\
\hline Polylepis racemosa & Queuña & $X$ & & \\
\hline Polylepis microphylla & Queuña & & & $X$ \\
\hline Polylepis subsericans & Queuña & & & $\mathrm{X}$ \\
\hline Prunus serotina & Capuli & $X$ & & \\
\hline Sambucus peruviana & Sauco & $\mathrm{X}$ & & \\
\hline Salix humboldtiana & Sauce & $\mathrm{X}$ & & \\
\hline Alnus acuminata & Aliso & & $\mathrm{X}$ & \\
\hline Caesalpinea spinosa & Tara & & $\mathrm{X}$ & \\
\hline Cantuta buxifolia & Cantuta & & $\mathrm{X}$ & \\
\hline Senna birrostris & Mut'uy & & $\mathrm{X}$ & \\
\hline Escallonia herrerae & Chachacomo & & & $\mathrm{X}$ \\
\hline Acalipha aronioides & $\mathrm{P}^{\prime}$ ispita & & & $\mathrm{X}$ \\
\hline Schinus molle & Molle & & & $\mathrm{X}$ \\
\hline Hesperomeles lanuginosa & Mayu manzana & & & $\mathrm{X}$ \\
\hline Hesperomeles latifolia & Lenle & & & $\mathrm{X}$ \\
\hline Myrcianthes oreophilla & Unca & & & $\mathrm{X}$ \\
\hline $\begin{array}{l}\text { Citharexylon } \\
\text { argutedentatum }\end{array}$ & Kuruchu & & & $\mathrm{X}$ \\
\hline Kageneckia lanceotata & Lloque & & & $X$ \\
\hline
\end{tabular}

Fuente: Elaborado en base a experiencias de campo 

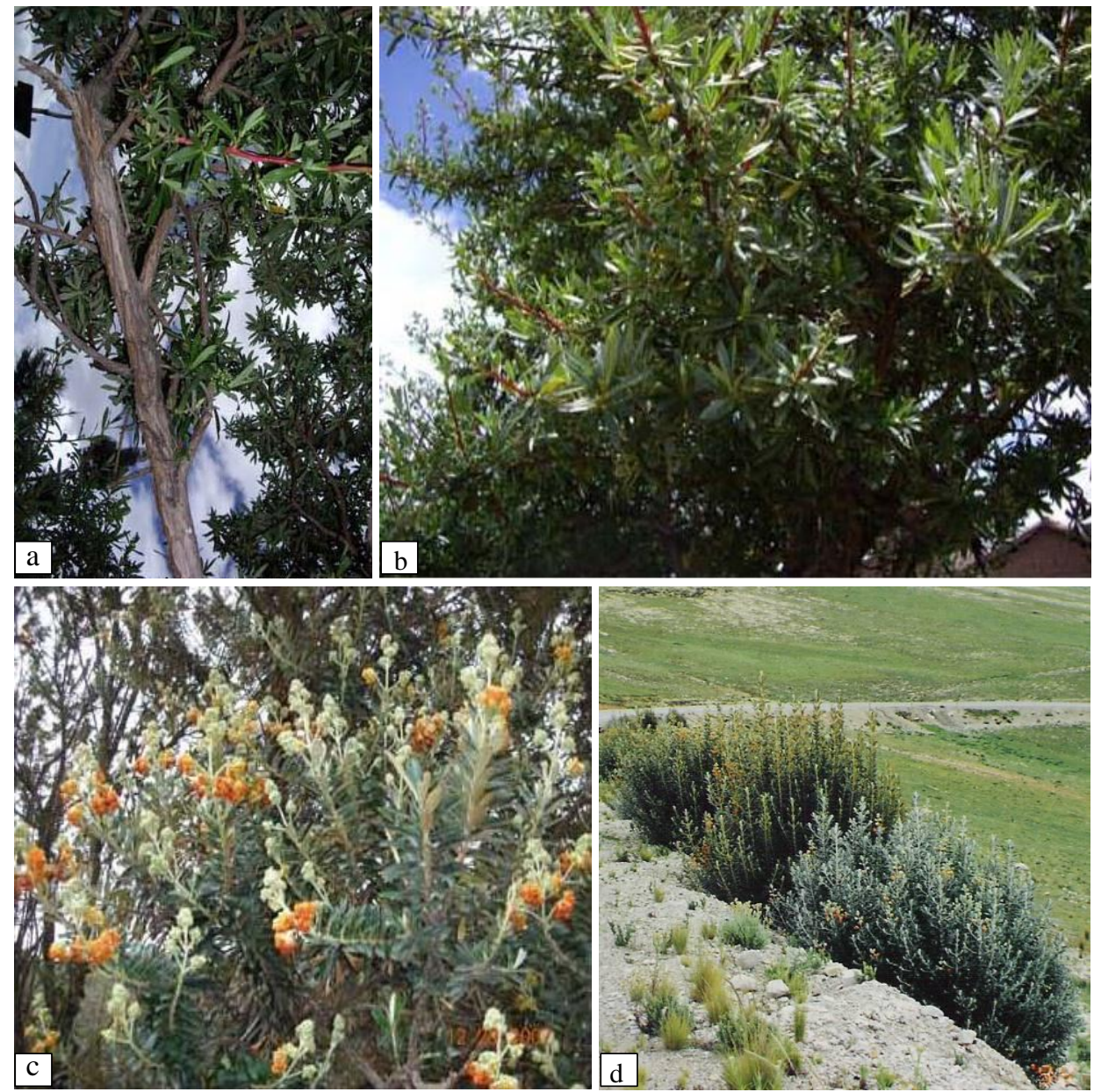

Figuras 5A-D. A,B: Chachacomo (Escallonia spp) es una especie representativa de los bosques mixtos montanos. C,D: $Q$ 'olle (Buddleja coriacea) constituye una especie adaptada a zonas xerofíticas de altura.

\section{DISCUSIÓN}

Coincidimos con Morrone, (2001), quien sustenta que las especies de plantas que crecen en los ecosistemas de Los Andes, se encuentran bien adaptadas a las condiciones climáticas predominantes; nuestros estudios tipifican que las especies adaptadas a los altos andes como el chachacomo (Escallonia resinosa), la queuña (Polylepis spp.), tayanka (Baccharis odorata), t'asta (Escallonia myrtilloides), lenle (Hesperomeles latifolia), aliso (Alnus acuminata), unca (Myrcianthes oreophilla), chiqllurmay (Vallea stipularis), k'uruchu (Citharexylon argutedentatum), q'otokiswar (Gynoxys longifolia), lloque (Kageneckia lanceolada) son especies de importancia no sólo en la ecología de esta zona, sino en la supervivencia de sus habitantes.

Ratificamos lo manifestado por Kessler \& Driesch, (1993), cuando sostienen que los bosques andinos históricamente han sido fuertemente afectados por la actividad humana y lo siguen siendo; en efecto, los trabajos de campo han verificado que la actividad antrópica ha generado devastación y fragmentación de hábitats y hoy los bosques nativos constituyen parches aislados y se hallan en lugares de poco acceso al ganado y a la actividad agrícola.

No coincidimos con la afirmación de Graf, (1994) y, Villalba, (1995), quienes sostienen que el principal factor natural que rige el cambio en los bosques andinos es el clima; nuestras observaciones de campo y el trabajo junto a las comunidades nos indican que el principal factor de cambio es la actividad antrópica, la obtención de leña y madera, la introducción de especies exóticas y la erosión de suelos.

Nuestras observaciones de campo son coincidentes con la afirmación de Kessler \& Driesch, (1993) quienes sostiene que el crecimiento demográfico ha llevado a los grupos humanos cercanos a los bosques andinos a hacer uso, explotación y sobreexplotación de los recursos naturales, en especial de la madera; en efecto, estas actividades vienen agotando la oferta de leña y madera en bosques nativos altoandinos.

El resultado de nuestra investigación no es coincidente con la afirmación de la FAO, (2007) cuando sostiene el bosque sólo es fuente de leña; en esencia, madera bruta seca en trozos normalmente medianos a pequeños; aun cuando el bosque altoandino es fuente importante de leña; no obstante, también es fuente de madera para la construcción de la vivienda, herramientas y aperos agrícolas y utensilios de cocina.

La afirmación de la Corporación de Certificación de Leña (2009) que señala que, a diferencia de las fuentes de energía fósil, la combustión de leña tiene un efecto neutro sobre el balance de dióxido de carbono ( $\mathrm{C} 02)$ en la atmósfera; consideramos que la tala, quema y cambio de uso del suelo no sólo generan deterioro ambiental, sino que contribuyen a la generación de gases de efecto invernadero; por lo tanto, la reforestación con especies adaptadas a los ecosistemas andinos debe ser una prioridad. Los estudios de Hensen (1991), señalan que el 50\% de las plantas para herramientas vienen del bosque y que las especies de Polylepis son las más utilizadas como especie provisora de leña y madera para aperos agrícolas; nuestros estudios reportan que existen 
diversas especies provenientes del bosque que son utilizadas en la fabricación de herramientas y aperos agrícolas; los informantes señalan hasta 10 especies nativas.

Ocaña (1996), plantea que, a través del Ministerio de Agricultura, se intensifique la reforestación y forestación, debido a que estas acciones contribuyen a que las poblaciones rurales tengan el suficiente material leñoso para el uso en sus viviendas; en efecto, la disminución de la oferta de leña y madera proveniente de bosques nativos, cada vez es menor observándose un déficit que debe ser suplido con leña de eucalipto.

Reynel y León (1990) mencionan que los cercos vivos para el cobijo de los cultivos es una práctica extensamente difundida en la Región Andina y alrededor del predio o chacra se establece un cinturón de plantas leñosas, predominantemente arbustivas o arbóreas; esto no es posible observar en el ámbito de estudio, pues la provisión de leña y madera, usualmente es obtenido de los bosques nativos.

\section{CONCLUSIONES}

Los bosques andinos son complejas formaciones de vegetación tropical de altura y están integrados por especies adaptadas a las condiciones climáticas de los Andes y son relativamente estables en estos hábitats. Sin embargo, estos bosques cambian por las condiciones ambientales y por la influencia del hombre.

La dependencia de las comunidades campesinas a los recursos provenientes del bosque nativo muestra claramente la importancia de las áreas boscosas para la vida campesina y la necesidad de una forma de manejo, que permita el uso por los campesinos en forma sostenible.

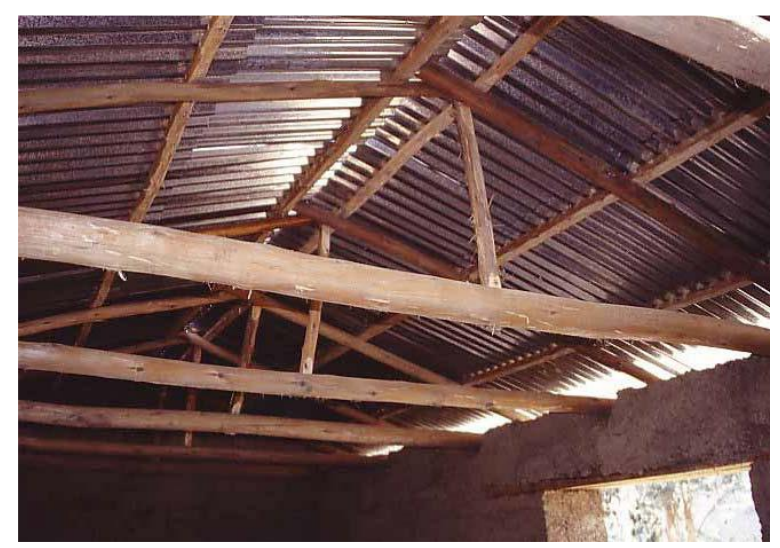

Figura 6. Estructura de eucalipto (Eucaliptus globulus) necesaria para sostener el peso de las planchas metálicas del techo.

La vegetación representativa del ámbito de estudio está formada por matorral espinoso, bosques mixtos y monoespecíficos de distribución restringida, que tipifica a ecosistemas y hábitats de interés ecológico, climático y biogeográfico. Sin embargo, y a pesar de su importancia biológica, estos bosques, representan uno de los hábitats más vulnerables de los altos Andes, por la creciente presión humana debido a factores económicos, sociales, y culturales $\mathrm{y}$ en un franco proceso de deterioro irreversible sino se acometen acciones para su recuperación.

El género Polylepis es representativo de los bosques andinos, tanto por su amplia distribución como por su afinidad al tipo de ambientes, siendo casi exclusivo de las zonas altoandinas. Las comunidades rurales andinas tienen una relación muy especial con los bosques. Su desarrollo cultural está en armonía con el entorno forestal y su identidad es el producto de su vida vinculada al bosque. La problemática del manejo de los recursos forestales en la zona andina afecta tres componentes: el suelo, el agua y, productos secundarios del bosque, los mismos que están íntimamente relacionados e integrados en su existencia con el hombre y la satisfacción de sus necesidades.

Las comunidades campesinas saben que los bosques y árboles son importantes y que son capaces de administrarlos y han mostrado lo siguiente:

- Los campesinos han acelerado la plantación y protección de los árboles tanto en sus propiedades como en los bosques comunales.

- Los campesinos conocen en gran medida las técnicas de propagación para las principales especies.

- Algunas comunidades han emprendido acciones colectivas sin ayuda externa para administrar mejor las tierras comunales.

- Las comunidades han desarrollado sus propias reglas y regulaciones que incluyen beneficios y sanciones para proteger y usar los bosques comunales.

En el ámbito de estudio las prácticas de aprovechamiento de los recursos del bosque son todavía eminentemente extractivas, sin consideración efectiva por la sostenibilidad de los productos del bosque. Sin embargo, los comuneros asienten que se requiere incrementar sus conocimientos respecto de la importancia de manejar los recursos del bosque y su directa dependencia para satisfacer sus principales necesidades de energía.

Referente al análisis y percepción de los bosques comunales y matorrales desde donde, los campesinos obtienen leña y madera, los comuneros identifican como problemática tres grandes causas: la extracción de leña y madera sea para uso doméstico o para la venta; la deforestación provocada por el avance de la frontera agrícola $\mathrm{y}$, los incendios forestales que no permiten que la regeneración natural del bosque ocurra.

Las especies mejor consideradas por su poder calorífico, pocos residuos de ceniza y poca producción de humo en su combustión son: chachacomo, queuña, t'asta, unca, k'uruchu, lloque, lenle, aliso, entre la vegetación arbórea y waka asta, llaulli e incluso la retama, entre los arbustos. Además, el chachacomo, t'asta, unca, qolle, aliso, chiqllurmay y queuña son maderas apreciadas para la construcción de infraestructura, aperos agrícolas y herramientas.

El número de especies utilizadas como leña ha disminuido con los años dentro del proceso de deterioro paulatino del bosque y matorral nativos. Sin embargo, se ha incrementado ostensiblemente el empleo del eucalipto, aspectos que deben de ser considerados en la propuesta de un programa de reforestación con fines energéticos.

Constituye una necesidad de las comunidades campesinas el contar con especies que posibiliten satisfacer los requerimientos para la construcción de la vivienda, principalmente referente al techado; especies como el aliso, chachacomo, unca, chiqllurmay, lenle y en los últimos 20 años el eucalipto son los más utilizados; esta última especie, ha cuadruplicado su uso y de las otras ha disminuido drásticamente; esto conduce a planificar programas de reforestación con especies que hace algunas décadas empleaban con éxito para estos menesteres.

Las estrategias que se sugieren para el ahorro de combustible tienen los siguientes enfoques: primero, elevar la oferta de leña y madera desde los bosques nativos y plantaciones en macizo a través de un programa de reforestación con fines energéticos; segundo, disminuir la demanda y uso de leña mediante la incorporación de fogones 
mejorados; tercero, gestionar los bosques con participación comunal incluyendo actividades industriales en la transformación de los productos del bosque; cuarto, introducir acciones para el cambio en los hábitos de cocción de alimentos del poblador andino.

El establecimiento de áreas forestales en terrenos comunales podría proveer a sus pobladores con madera, leña, postes, palos, madera para la fabricación de aperos agrícolas y utensilios y, madera para la construcción de viviendas. Desafortunadamente, no se plantan suficientes árboles y los que son plantados carecen de los cuidados necesarios. Por lo tanto, se requiere actuar con inmediatez a fin de recuperar la cobertura vegetal arbórea con estos fines.

Las especies nativas más utilizadas como combustible son chachacomo (Escallonia resinosa), queuña (Polylepis spp.), tayanka (Baccharis odorata), t'asta (Escallonia myrtilloides), lenle (Hesperomeles latifolia), aliso (Alnus acuminata), unca (Myrcianthes oreophilla), chiqllurmay (Vallea stipularis), k'uruchu (Citharexylon argutedentatum), q'otokiswar (Gynoxys longifolia), lloque (Kageneckia lanceolada) y otras especies nativas, los que por ser de madera dura y tener alto poder calorífico son las preferidas.

\section{SUGERENCIAS}

\section{Posibles soluciones para la deforestación por consumo de} leña

Las soluciones o estrategias que se diseñen para transformar el consumo de leña en una actividad sustentable a largo y mediano plazo, deberán ser de un carácter diverso y dinámico. A pesar de que la disponibilidad general del recurso leña, es decir, la oferta de biomasa vegetal por los bosques nativos es diversa; es el caso de que en la microcuenca del río Patacancha que proporciona leña y madera para Ollantaytambo, Phallata e incluso Willoq sobrepasa al consumo en la actualidad; igual observación se puede hacer para la microcuenca de los ríos Lares y Trapiche donde la oferta de leña es mayor al consumo actual. Análogamente ocurren casos donde la oferta de leña es escasa frente a la demanda por las comunidades campesinas como en aquellas ubicadas por encima de los 4000 metros de altitud; sin embargo, es importante señalar que no todo el recurso potencial es accesible y que su disponibilidad varia espacialmente, lo que reduce significativamente el stock disponible de manera efectiva en muchas comunidades andinas.

De otro lado, es necesario considerar el crecimiento de la población, el aumento en el consumo y la degradación del recurso, si no se acometen acciones concretas para mejorar la oferta de leña y disminuir el consumo per cápita, será inevitable que la presión por el uso de leña y madera continúe aumentando. Consecuentemente es necesario introducir acciones de forestación y reforestación a efecto de incrementar la producción anual del bosque nativo. Esta situación indica que se pueden tomar iniciativas y emprender acciones para que el consumo de leña sea más sustentable y aprovechar mejor los recursos provenientes del bosque nativo.

Por otra parte, las posibles soluciones deben resolver una diversidad de problemas que tienen causas diferentes y, por lo mismo, deben ser diversas y dinámicas. Estas soluciones deben orientarse a tres tipos de situaciones:

- Primero, aquellas relacionadas al consumo doméstico en el sector rural incluyendo el ahorro en combustible a través del uso del recurso leña en condiciones óptimas; es decir, con menor contenido de humedad, introducción de cocinas mejoradas y el cambio en los hábitos alimentarios. En este caso la leña es un recurso de bajo costo.

- Segundo, aquellas vinculadas al uso de la leña para las áreas urbanas en el piso de valle, específicamente en el Valle Sagrado (Ollantaytambo, Urubamba, Calca, Pisaq) donde la demanda de leña es cada vez mayor para el uso de los restaurantes que poseen un crecimiento continuo. Donde el recurso leña constituye una mercancía, por lo tanto, forma parte de los ingresos económicos eventuales de algunas familias campesinas.

- Tercero, las acciones vinculadas al manejo sustentable del bosque a través de un programa de gestión comunal en materia de forestación y reforestación.

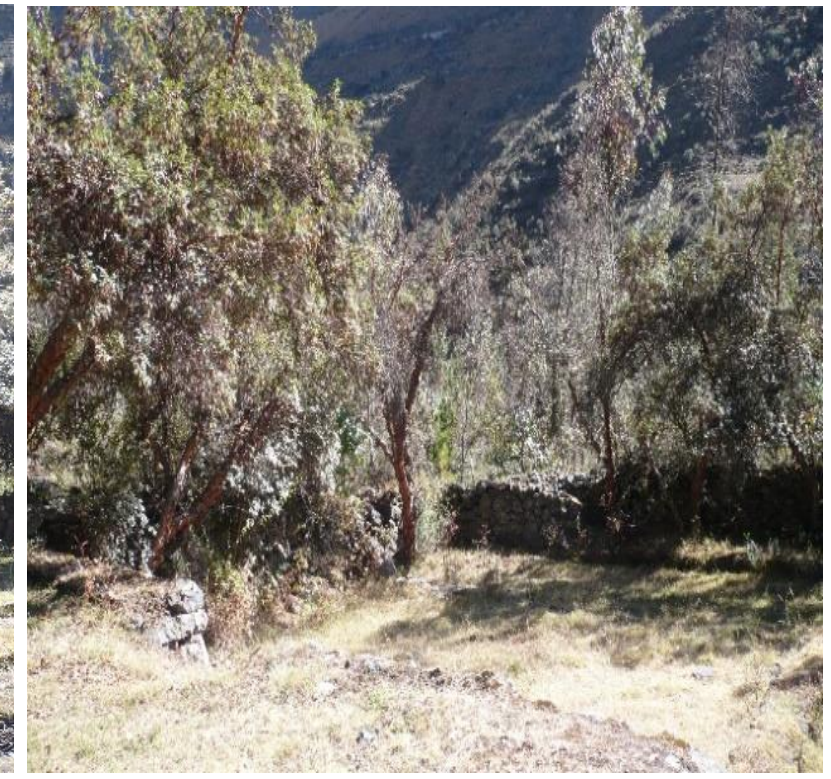

Figura 7. El k'urucho (Citharexylon argutedentatum) es una de las especies más apreciadas por el poder calorífico que posee su leña. Debe ser una de las especies a ser utilizada en la reforestación de los altos Andes. 
Existen ventajas comparativas del uso de los recursos forestales provenientes de bosques comunales; en principio, la leña como combustible, es una energía local, producida en el bosque de la comunidad; es, además, una energía renovable. Los bosques crecen todos los años y si se extrae de ellos una cantidad inferior a su crecimiento, se podrá aprovechar esta energía en forma indefinida. De otro lado, las especies nativas, poseen un alto poder calorífico. Además, existen otras ventajas del uso de las especies nativas: generan mayor volumen de brasa, contienen menor cantidad de cenizas que el eucalipto y, el proceso de secado es más rápido comparativamente con el eucalipto.

\section{Hacia una política dendroenergética}

En un país como Perú, que aún tiene una gran cantidad de población viviendo en áreas rurales, más de 7 millones de personas poseen casi como único recurso energético a la leña, y donde extensas áreas han sido ya deforestadas, es urgente buscar y encontrar soluciones de corto, mediano y largo plazo. Los diversos niveles del gobierno deben emprender programas regionales de forestación y reforestación con fines energéticos, industriales, gestión de cuencas hidrográficas y recuperación de ecosistemas degradados; de esta forma, se incrementaría la producción de los bosques nativos, generando trabajo para las poblaciones locales y promocionando el empleo de recursos energéticos en base a biomasa renovable.

Existen aspectos positivos de la dendroenergía que los mencionamos:

Ambientales. A diferencia de las fuentes de energía fósil, la combustión de leña tiene un menor efecto respecto de las emisiones de dióxido de carbono (CO2) a la atmósfera; a nivel local, la leña tiene un efecto ambiental positivo pues permite cubrir parte de los costos involucrados en el manejo y conservación de bosques; por lo tanto la reforestación y forestación con especies altamente consumidas y provenientes de bosques nativos no sólo controlaría la erosión de suelos y la escorrentía superficial, sino que tendría efectos benéficos en las poblaciones rurales. En este contexto, la conservación de los recursos naturales y calidad del aire, forman también parte de esta actividad, pues la producción y el uso de biomasa forestal deben evitar la generación de externalidades ambientales negativas. No es sostenible la degradación del bosque nativo para producir leña, como tampoco lo es la tala de plantaciones forestales que producen erosión, disminución de la calidad y cantidad del agua, entre otros efectos. Tampoco es sostenible la contaminación del aire en áreas urbanas que amenaza la salud de la población. Para que la biomasa forestal sea considerada una fuente de energía renovable no debe atentar contra el ambiente ni el bienestar de la población.

Socioeconómicas. El mercado de la leña genera un flujo importante en las poblaciones del piso de valle, debido a la demanda en el sector de restaurantes. El rubro puede dar empleo a cientos de personas, principalmente del sector económico más deprimido. Este efecto sobre el empleo tiene creciente importancia local y regional, pues la leña no sólo es producida y comercializada localmente, sino que las herramientas y equipos requeridos para su combustión son fabricados a nivel local. El trabajo de campo y el diálogo sostenido con los campesinos nos conduce a la conclusión de que para el sector rural no es económicamente factible reemplazar la leña por gas natural, dado las diferencias en los precios.

Energéticas. La dendroenergía ha sido reconocida mundialmente como una alternativa energética más limpia, segura y económica, que puede además transformarse en electricidad y en combustibles líquidos y gaseosos (biocombustibles de segunda generación). Además, es una fuente de energía local sobre la cual el Perú tiene soberanía. El uso masivo de leña en el país tendría un efecto positivo y sinérgico sobre el clima global, la economía nacional y los mercados locales en el área rural y urbana. Si los gobiernos locales y regionales optaran por una masiva acción de reforestación con especies vinculadas a la generación de leña y madera a fin de incrementar la oferta de los bosques nativos comunales, no sólo se generaría trabajo, sino la recuperación de ecosistemas degradados en los altos andes.

\section{REFERENCIAS BIBLIOGRÁFICAS}

Cabrera, A. \& A. Willink. (1973). Biogeografía de América latina. OEA, Washington, pp 83-96.

Casas Anguita, J.; Repullo Labrador, J.R. y Campos, J. Donado. (2002). La encuesta como técnica de investigación. Elaboración de cuestionarios y tratamiento estadístico de los datos. Departamento de Planificación y Economía de la Salud. Escuela Nacional de Sanidad. Madrid. España.

Corporación de Certificación de Leña. (2009). Lineamientos para una política de dendroenergía corporación de certificación de leña. Estado del arte, objetivos y propuestas. En: V Cumbre de la leña, Castro-Chiloé. 35 p.

Etter, A; Villa, L.A. (2000). Andean forests and farming systems in part of the Eastern Cordillera (Colombia). Mt Res Dev 20(3):236-245.

FAO. (2006). Situación de los bosques del mundo 2005. Roma.

FAO. (2007). Los sistemas de la dendroenergía sostenible. Departamento Forestal. Roma.

FAO. (2008a). Bosques y energía. Cuestiones clave. Estudio FAO Montes 154. Roma. 86p.

FAO. (2008b). Biocombustibles y calentamiento global. Disponible http:1/biocombustibles.blogspot.com/2008/06/definicin-deladendroenerga. html.

FAO. (2009). Situación de los bosques en el mundo. 2009. Roma. 158 p.

Fittkau, E., J. Illies, H. Klinge, G. Schwabe \& H. Sioli. (1968). Biogeography and ecology in South America. Junk Publishers, Netherlands, pp 39, 56-59, 66, 75-78, 82-84, $106,109,115,450,452,460-469$.

Fjeldsa, J. \& M. Kessler. (2004). Conservación de la biodiversidad de los bosques de Polylepis de las tierras altas de Bolivia. Una contribución al manejo sustentable en los Andes. DIVA Technical Report 11. Editorial FAN. Santa Cruz de la Sierra. $214 \mathrm{p}$

Gehu, J.M-Pedrotti, F-Pignatti, S-Rivas Martines, S-Hubl E. (1992). Mountain Vegetation. Proceedings of the Internacional Symposium, Beijing. Departamento di Botanica ed Ecologia dell'Universitá. Camerino, Italia.

Gil, J.E., Baca, J.A y, Álvarez, M.E. (2020). Consumo de leña y estimaciones del valor calorífico de especies de plantas utilizadas por las comunidades campesinas de la cordillera del Vilcanota, Cusco. Revista Queuña. Cusco.

Heising, Klas. (2006). Diversidad de combustibles domésticos en el Perú y la falta de cocinas apropiadas. Tresco Andes. lima -Perú. $12 \mathrm{p}$.

Graf, K. (1994). Vegetación y clima de los Andes bolivianos durante la última época glacial. Ecología en Bolivia 23: 119.

Hensen, I. (1991). La flora de la comunidad de Chorojo, su uso, taxonomía científica y vernacular. AGRUCO, Cochabamba. $26 \mathrm{p}$.

Hurtado, J. (2007). Esquema para una Investigación Analítica, Disponible en: http://aprenderlyx.com/tipos-demetodologia-de-investigacion/ 
INEI. (2005). Información del Censo de Población y Vivienda. Lima.

INEI. (2009). Perú: Estimaciones y Proyecciones de Población Total por Sexo de las Principales Ciudades, 2000-2015. Capítulo I: Metodología. pp 9-13. Lima.

Jussieu (1993). En: Killeen, T. J.; García E.; Beck S. G. editores. Guía de árboles de Bolivia, 1993. Herbario Nacional de Bolivia-Missouri Botanical Garden. 958 pp. La Paz.

Kessler, M. \& P. Driesch. (1993). Causas e historia de la destrucción de bosques altoandinos en Bolivia. Ecología en Bolivia 21: 1-18.

MINAM/INEIIPNUMA. (2009). Perú 2008. Indicadores. Iniciativa Latinoamericana y caribeña para el Desarrollo Sostenible: Indicadores de seguimiento. lima -Perú. $88 \mathrm{p}$.

MINAM/INEI/PNUD. (2009). Iniciativa Latinoamericana y caribeña -Indicadores de Seguimiento: Perú 2008.lima Perú. 88 p.

Ministerio de Agricultura y Riego-MINAG. (2009). Plan nacional de agro energía 2009-2020. Lima, 29 pp.

Ministerio de Energía y Minas-MINEM. (2007). Balance Nacional de Energía 2006. Oficina de Planeamiento, Inversiones y Cooperación Internacional. Lima -Perú. 199 p.

Morrone, J. (2001). Biogeografía de América latina y el Caribe. CYTED, ORCYT-UNESCO, SEA, Zaragoza, pp $13-133$.

Muñoz Zegarra, Madeleine. (2008). Promoviendo Cambios Sostenibles para la Equidad de Género y el Desarrollo Social a través de las Cocinas Mejoradas. Sistematización de Experiencias. Documento de trabajo $\mathrm{N}^{\circ}$ 5. Lima - Perú. 58 p.

Navarro, G., J. Molina \& De La Barra, N. (2005). Classification of the High-Andean Polylepis forests in Bolivia. Plant Ecology.

Ocaña David. (1996). Desarrollo Forestal Campesino en la Región Andina del Perú. Proyecto Apoyo a las Plantaciones
Forestales con Fines Energéticos y para el Desarrollo de las Comunidades Rurales - FAO/Holanda/PRONAMACHCS.

Purcell J. \& A. Brelsford. (2004). Reassessing the causes of decline of Polylepis, a tropical subalpine forest. Ecotropica 10: $155-158$.

Reinel R. Carlos y León G. Jaime. (1990). Árboles y Arbustos Andinos para la Agroforesteria y Conservación de Suelos T I - II. Proyecto FAO/Holanda /DGFF. Lima Perú.

Sánchez, F. (2019). Fundamentos epistémicos de la investigación cualitativa y cuantitativa: Consensos y disensos. Recuperado de: http://www.scielo.org.pe/scielo.php?pid=S2223$25162019000100008 \&$ script=sci_arttext

Sentir.org. (2001). Selva andina o bosque de niebla. Programa Regional para la Gestión Social de Ecosistemas Forestales Andinos ECOBONA. Quito.Smithsonian National Museum of Natural History. (2000). Tropical Andes: CPD Site SA37 Eastern slopes of Peruvian Andes.

Suárez Correa, J. C. (2014). La dendroenergia en la amazonia peruana. Tesis, Universidad Nacional de Cajamarca. Cajamarca.

Thorson, R. (1999). El límite glacial en Sudamérica y su papel en biogeografía: observaciones de Darwin. Geociencias.

Van der Hammen, T. \& A.M. Cleef. (1986). Development of the high páramo flora and vegetation. 153-199. En: Vulleumier, F. \& M. Monasterio (eds.), High Altitude Tropical Biogeography. Oxford University Press, New York.

Villalba, R. (1995). Geographical variations in tree-growth responses to climate in the southern Andes. 307-317. En: Argollo, J. \& P. Mourguiart (eds.), Climas Cuaternarios En América Del Sur. ORSTOM, La Paz.

Presentado: 01/07/2021 Aceptado: 29/07/2021 Publicado: 31/01/2022 